\title{
Cellular in vitro bioactivity of protein hydrolysates from brewers' spent grain
}

\author{
A. L. McCarthy ${ }^{1}$, Y. C. Ocallaghan ${ }^{1}$, A. Connolly ${ }^{2}$, C. O. Piggott ${ }^{2}$, R. J. Fitzgerald ${ }^{2}$ and N. M. Obrien ${ }^{1}$ \\ ${ }^{1}$ School Of Food and Nutritional Sciences, University College Cork, Ireland and ${ }^{2}$ Department of Life Sciences, \\ University of Limerick, Ireland
}

Protein hydrolysates have been used as components of nutrition products, including geriatric and sports products, and in weight-control diets $^{(1)}$. Brewers' spent grain (BSG), a co-product of the brewing industry, represents a unique source of protein hydrolysates. The aim of this study was to assess the in vitro bioactivity of BSG hydrolysates and fractionated hydrolysates.

Hydrolysates (designated U-W) were prepared from BSG using either Alcalase 2.4L, Corolase PP or Flavourzyme. Cytotoxicity was measured using the 3-(4,5-dimethylthiazol-2-yl)-2,5-diphenyltetrazolium bromide (MTT) assay in both U937 and Jurkat T cells. The antioxidant activity of the hydrolysates was determined in U937 cells by two methods - ability to protect against hydrogen peroxide $\left(\mathrm{H}_{2} \mathrm{O}_{2}\right)$-induced $(100 \mu \mathrm{M} 60 \mathrm{~min})$ oxidative stress, by the SOD assay and $\mathrm{H}_{2} \mathrm{O}_{2}$-induced $(50 \mu \mathrm{M} \times 30 \mathrm{~min})$ DNA damage, by the comet assay. An enzyme-linked immunosorbent assay (ELISA) was used to measure the effect of the samples on concanavalin-A (con-A) stimulated production of interferon- $\gamma$ (IFN- $\gamma$ ) in Jurkat $\mathrm{T}$ cells, indicating their immunomodulatory potential.

\begin{tabular}{|c|c|c|c|c|c|c|}
\hline & \multicolumn{2}{|c|}{ SOD activity ( $\%$ of control) } & \multicolumn{2}{|c|}{ DNA damage ( $\%$ tail DNA) } & \multicolumn{2}{|c|}{ IFN- $\gamma$ production ( $\%$ of control) } \\
\hline & Mean & $\mathrm{se}$ & Mean & se & Mean & $\mathrm{se}$ \\
\hline Control & 100.0 & 0.0 & 5.1 & 0.6 & 100.0 & 0.0 \\
\hline $\mathrm{H}_{2} \mathrm{O}_{2}$ control & $57.2 *$ & 0.7 & $41.8 *$ & 4.8 & $\mathrm{n} / \mathrm{a}$ & $\mathrm{n} / \mathrm{a}$ \\
\hline $\mathrm{U}$ & 67.2 & 5.4 & 52.2 & 5.3 & $77.7 \dagger$ & 2.3 \\
\hline $\mathrm{U}<3 \mathrm{kDa}$ & 101.9\# & 4.9 & 42.3 & 2.3 & 98.1 & 2.8 \\
\hline $\mathrm{U}<5 \mathrm{kDa}$ & $111.5 \#$ & 3.3 & 41.3 & 1.8 & 102.6 & 3.8 \\
\hline $\mathrm{U}>5 \mathrm{kDa}$ & $80.5 \#$ & 4.3 & 43.7 & 3.1 & $82.0 \dagger$ & 2.3 \\
\hline $\mathrm{V}$ & 62.8 & 3.5 & 46.3 & 3.6 & $86.9 \dagger$ & 1.4 \\
\hline $\mathrm{V}<3 \mathrm{kDa}$ & 65.9 & 7.1 & 37.3 & 5.5 & 99.6 & 2.1 \\
\hline $\mathrm{V}<5 \mathrm{kDa}$ & 67.2 & 4.1 & 33.2 & 4.0 & 105.6 & 3.6 \\
\hline $\mathrm{V}>5 \mathrm{kDa}$ & 92.0\# & 2.8 & 32.7 & 5.1 & $81.3 \dagger$ & 2.1 \\
\hline W & 70.8 & 4.2 & 39.2 & 0.7 & $87.3 \dagger$ & 1.5 \\
\hline $\mathrm{W}<3 \mathrm{kDa}$ & $124.4 \#$ & 2.9 & 29.1 & 3.1 & 113.5 & 4.1 \\
\hline $\mathrm{W}<5 \mathrm{kDa}$ & 87.7\# & 3.5 & 24.0\# & 4.7 & 95.12 & 3.2 \\
\hline $\mathrm{W}>5 \mathrm{kDa}$ & 108.4\# & 1.8 & 37.3 & 3.5 & $78.6 \dagger$ & 1.6 \\
\hline
\end{tabular}

BSG protein hydrolysates were more cytotoxic in U937 than in Jurkat T cells (data not shown). Addition of $\mathrm{H}_{2} \mathrm{O}_{2}$ to $\mathrm{U} 37$ cells decreased SOD activity to $57.2 \%$ and increased $\%$ tail DNA to approximately $41.8 \%(P<0.05)$. Lowest molecular weight (m.w.) hydrolysates $(<3,<5 \mathrm{kDa})$ showed strong protection against SOD reduction $(P<0.01)$, particularly for fractionated hydrolysates of U and W. Only $\mathrm{W}<5 \mathrm{kDa}$ significantly $(P<0.01)$ repaired $\mathrm{H}_{2} \mathrm{O}_{2}$-induced DNA damage. Contrastingly, unfractionated hydrolysates and hydrolysates with higher m.w. $(>5 \mathrm{kDa})$ possessed significant $(P<0.05)$ anti-inflammatory potential, reducing IFN- $\gamma$ production by up to $22.3 \%$.

In conclusion, this study suggests BSG protein hydrolysates have bioactive potential; with low m.w. and higher m.w. fractionated hydrolysates demonstrating antioxidant and anti-inflammatory effects, respectively. These hydrolysates represent novel bioactive ingredients for inclusion in functional foods.

Funding for this research was provided under the National Development Plan, through the Food Institutional Research Measure, administered by the Department of Agriculture, Food and the Marine, Ireland.

1. McCarthy AL, OCallaghan YC \& OBrien NM (2013) Agriculture 3, 112-130. 